OPEN ACCESS

Edited by:

Karl Kuchler,

Medical University of Vienna, Austria

Reviewed by:

Yang Cheng,

Jiangnan University, China

Jun-Hu Chen,

National Institute of Parasitic

Diseases, China

Alberto Moreno,

Emory University, United States

${ }^{*}$ Correspondence:

Wenyue $X_{u}$

xuwenyue@tmmu.edu.cn

Taiping Liu

liutaiping@tmmu.edu.cn

tThese authors have contributed equally to this work

Specialty section:

This article was submitted to Infectious Diseases,

a section of the journal

Frontiers in Microbiology

Received: 22 February 2021

Accepted: 08 April 2021

Published: 30 April 2021

Citation:

Cai J, Chen S, Zhu F, Lu X, Liu T and Xu W (2021) Whole-Killed Blood-

Stage Vaccine: Is it Worthwhile to

Further Develop It to Control Malaria?

Front. Microbiol. 12:670775.

doi: 10.3389/fmicb.2021.670775

\section{Whole-Killed Blood-Stage Vaccine: Is It Worthwhile to Further Develop It to Control Malaria?}

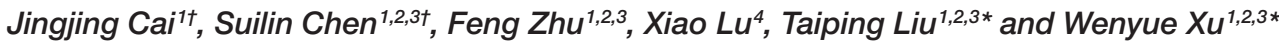 \\ ${ }^{1}$ College of Basic Medicine, Army Medical University (Third Military Medical University), Chongqing, China, ${ }^{2}$ Department of \\ Pathogenic Biology, Army Medical University (Third Military Medical University), Chongqing, China, ${ }^{3}$ Key Laboratory of \\ Extreme Environmental Medicine, Ministry of Education of China, Chongqing, China, ${ }^{4}$ Department of Thoracic Surgery, \\ Xinqiao Hospital, Army Medical University (Third Military Medical University), Chongqing, China
}

Major challenges have been encountered regarding the development of highly efficient subunit malaria vaccines, and so whole-parasite vaccines have regained attention in recent years. The whole-killed blood-stage vaccine (WKV) is advantageous as it can be easily manufactured and efficiently induced protective immunity against a blood-stage challenge, as well as inducing cross-stage protection against both the liver and sexualstages. However, it necessitates a high dose of parasitized red blood cell (pRBC) lysate for immunization, and this raises concerns regarding its safety and low immunogenicity. Knowledge of the major components of WKV that can induce or evade the host immune response, and the development of appropriate human-compatible adjuvants will greatly help to optimize the WKV. Therefore, we argue that the further development of the WKV is worthwhile to control and potentially eradicate malaria worldwide.

Keywords: malaria parasite, whole-killed blood-stage vaccine, liver stage, sexual-stage, blood stage

\section{INTRODUCTION}

Malaria remains a potentially fatal public health problem, resulting in high morbidity and mortality in tropical and subtropical regions. Recently, malaria control interventions, such as artemisinin-based combination therapy (ACT), insecticide-treated bed nets (ITNs), and other mosquito vector control strategies, have greatly reduced the incidence of malaria all over the world (O'Meara et al., 2010). However, the emergence of artemisinin derivative-resistant malaria parasites (Phyo et al., 2012; Uwimana et al., 2020) and insecticide-resistant mosquitoes (Ranson et al., 2011) has greatly hampered the effectiveness of ACTs and ITNs. Therefore, the development of a highly efficient malaria vaccine has been regarded as the most cost-effective tool for malaria control and elimination, and potentially even eradication (Crompton et al., 2010).

Malaria is caused by the infections of species in the Plasmodium genus. There are four human malaria parasites, namely, Plasmodium vivax (P. vivax), P. falciparum, P. ovale, and P. malariae. Of these, P. falciparum is the deadliest. A Plasmodium infection is initiated by sporozoite inoculation into the host skin by an infected female Anopheles mosquito. The sporozoites travel to the liver and infect a small number of hepatocytes, with a single sporozoite giving rise to tens of thousands of merozoites. Next, merozoites are released into the bloodstream when merosomes bud from an infected hepatocyte, and they invade red blood cells (RBCs), initiating blood-stage development. A merozoite can multiply up to 20 -fold every $1-3$ days in 
cycles of invasion, replication, and RBC rupture, which releases many infectious merozoites. Some of the asexual blood stages transform into sexual forms called as gametocytes, which can eventually move into the midgut of a blood-feeding mosquito and then develop into sporozoites in the salivary gland. The blood-feeding mosquito then injects these sporozoites into another human, thereby initiating a new human infection (Figure 1).

Thus, the Plasmodium life cycle involves the liver stage (pre-erythrocytic stage) and blood stage in mammals and the sexual-stage in its vector. The blood stage is the main cause of the clinical manifestations (ranging from mild to severe malaria), and a blood-stage vaccine aims to reduce mortality and morbidity in malaria patients. In contrast, the liver stage is clinically silent, and a liver-stage vaccine is promising for preventing malaria infection (Smith et al., 2012). The development of the parasite in mosquitoes is essential for malaria transmission. Therefore, a sexual-stage vaccine aims to block malaria transmission (Acquah et al., 2019; Figure 1). For each stage, two kinds of vaccines, namely subunit and whole-parasite vaccines, are being explored. As major challenges have been encountered regarding subunit malaria vaccines, whole-parasite vaccines have recently been regaining attention. Here, we discuss promising aspects regarding the development of a whole-killed blood-stage vaccine $(\mathrm{WKV})$ that protects against all stages and perspectives on its optimization in the future.

\section{MAJOR CHALLENGES HAVE BEEN ENCOUNTERED IN THE DEVELOPMENT OF A HIGHLY EFFICIENT SUBUNIT MALARIA VACCINE}

In the past three decades, great efforts have been made to develop efficient subunit vaccines against the pre-erythrocytic, blood, and sexual-stages, but major challenges have been encountered. The dominant protective antigen of the pre-erythrocytic stage is the main surface protein of sporozoites,

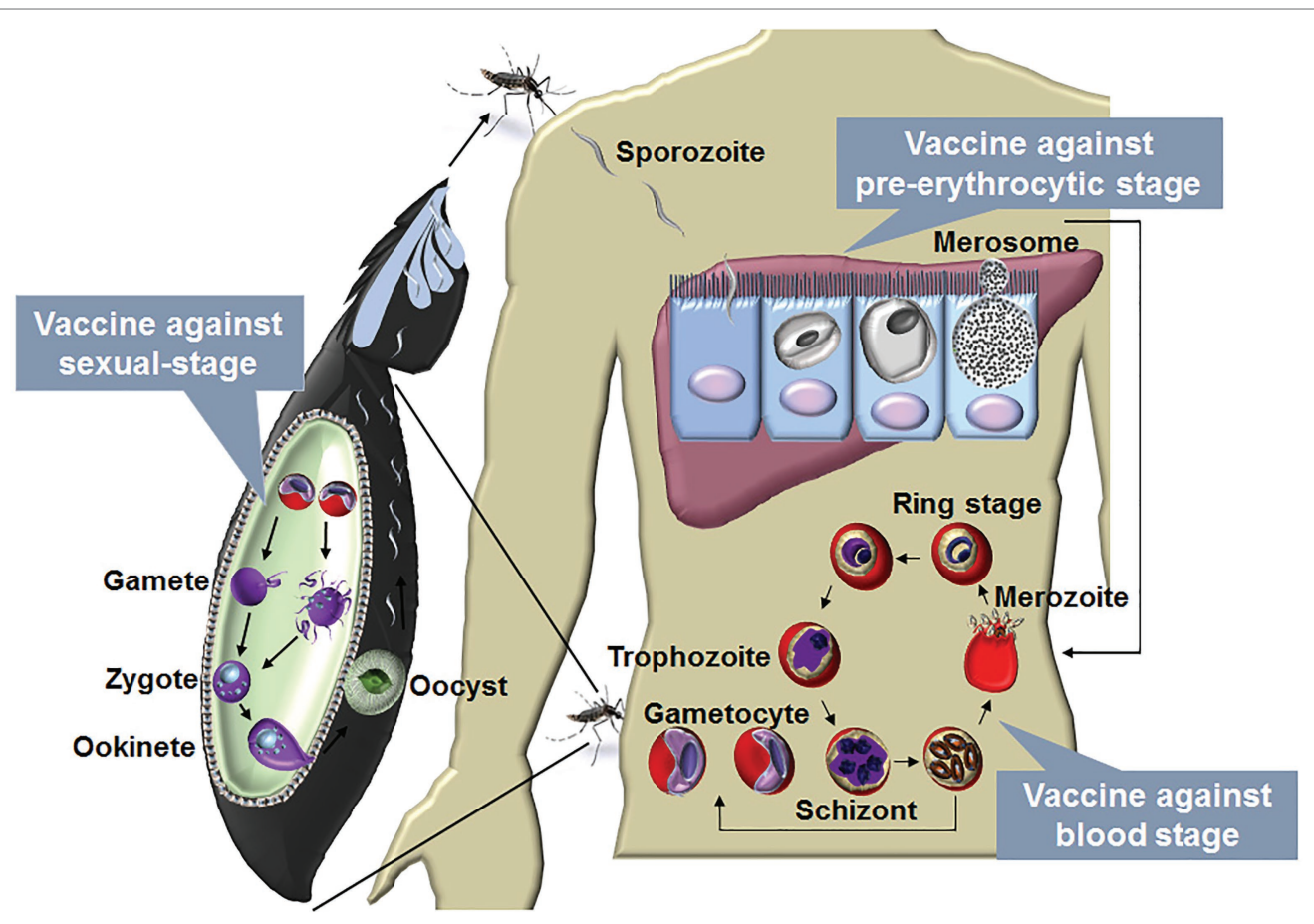

FIGURE 1 | The life cycle of malaria parasite and vaccines designed against each stage. The life cycle of Plasmodium includes liver stage and blood stage in human and sexual-stage in the mosquito vector. A Plasmodium infection begins when an infected female Anopheles mosquito takes a blood meal and injects a small number of sporozoites into a human host. The sporozoites enter blood vessels and invade target hepatocytes, with a single sporozoite giving rise to tens of thousands of merozoites. Next, merozoites are budded from an infected hepatocyte by the merosomes and rupture to release thousands of merozoites into the bloodstream. In the bloodstream, the merozoites invade RBCs, initiating blood-stage development. A merozoite, which subsequently develop into ring, trophozoite, and schizont stage parasites, can multiply up to 20-fold every 1 to 3 days in cycles of invasion, replication, and RBC rupture. New daughter merozoites are released and rapidly invade the non-infected erythrocytes. Within erythrocytes, some of the merozoites differentiate into sexual forms of the parasite, which are called as male or female gametocytes. When male and female gametocytes are picked up by a female Anopheles mosquito during a blood meal, they develop further into mature sexual stages called as gametes. Fertilization happens between the male and female gametes, giving rise to a zygote. The developing zygotes transform into elongated motile ookinetes, which invade through the midgut wall of the mosquito and form oocysts on the exterior surface. Once the oocysts have matured, they eventually burst, releasing thousands of sporozoites that migrate to the mosquito salivary glands ready to infect another human host during the next mosquito blood meal (Julien and Wardemann, 2019). A vaccine against the blood stage aims to reduce the mortality and morbidity of malaria patients, and vaccine against the liver stage is a promising method to prevent malaria infection. The development of the parasite in the vector is essential for transmission, a vaccine against the sexualstage aims, therefore, to block transmission of malaria parasites. 
circumsporozoite protein (CSP), which plays an important role in sporozoite invasion of hepatocytes (Dame et al., 1984; Rathore et al., 2002; Kumar et al., 2006). The most advanced CSP-based subunit malaria vaccine is RTS,S/AS01. This vaccine consists of a large part of the CSP fused with hepatitis B virus surface antigen (HBV-S Ag) particle formulated with the potent liposomal adjuvant AS01 (Cohen, 1996; Casares et al., 2010). Phase 3 clinical trials showed that the vaccine's protection efficacy was $50.4 \%$ against the first clinical episode of malaria and $45.1 \%$ against severe malaria in young children, but only $30.1 \%$ in infants (Agnandji et al., 2011, 2012). In 2015, the European Medicines Agency announced the adoption of a positive scientific opinion regarding the use of RTS,S in regions outside of the European Union, where malaria is a major problem (EMA, 2015). In 2019, the World Health Organization (WHO) recommended the large-scale pilot implementations of routine use of RTS,S in real-life settings, involving moderate-to-high malaria transmission in order to assess its protective benefits and safety (WHO, 2019). However, RTS,S/AS01 still does not meet the criteria for a licensable first-generation vaccine $(50 \%$ efficacy lasting for $\geq 1$ year; Crompton et al., 2010), as the vaccine efficacy was dropped to 28 and $18 \%$ at $3-4$ years post-vaccination in children and young infants, respectively (Rts, 2015). Therefore, the main challenge of the use of RTS,S is to sustain high antibody concentrations to mediate durable protection.

Most blood-stage candidate antigens are essential invasion proteins of merozoites such as merozoite surface protein (MSP1) and MSP3, apical membrane antigen 1 (AMA1), and erythrocytebinding antigen 175 (EBA-175). These blood stage malaria vaccine candidates seek to induce high titers of plasmodium specific antibody that inhibit erythrocyte invasion by merozoites or limit parasite replication in red blood cells. However, most of the vaccine candidates exhibit extensive polymorphism between malaria strains from different geographical regions, and immunization with these vaccines only led to partial protection against vaccine-like strains (Bull et al., 1998; Sutherland, 2007; Fowkes et al., 2010). In addition, the RBC invasion pathways of merozoite exhibit redundancy, with the blockade of one invasion pathway failing to confer protection against challenge (Ogutu et al., 2009; Sagara et al., 2009; Sirima et al., 2011). The leading vaccine candidates AMA1 did not provide significant protection against clinical malaria in vaccine trials, and an MSP3 vaccine in Burkinabe children also demonstrated short-term protection (Sirima et al., 2011; Thera et al., 2011). At present, the most promising blood-stage candidate antigen is $P$. falciparum reticulocyte-binding protein homolog 5 (PfRH5), which interacts with basigin (CD147) on the RBC surface during merozoite invasion (Wright et al., 2014). PfRH5 exhibits limited polymorphism, and PfRH5/basigin is essential for merozoite invasion of RBCs (Weiss et al., 2015; Volz et al., 2016). Pre-clinical studies showed that PfRH5 induced cross-strain neutralizing antibody (Douglas et al., 2011) and confers nearly complete protection against challenge with heterologous Plasmodium strains in Aotus monkeys (Douglas et al., 2015). Recent study has defined that the neutralizing and non-neutralizing epitopes of PfRH5 are both essential for red blood cell invasion by the merozoites, which will optimize the designation of PfRH5-based vaccine (Alanine et al., 2019). However, protection in monkeys required a high level of antiPfRH5 IgG (an estimated $200 \mu \mathrm{g} / \mathrm{ml}$ ), and there was modest or no boosting of vaccine-induced antibody by infection of the monkeys (Douglas et al., 2015). This may limit the efficacy and duration of protection conferred by a PfRH5-based subunit vaccine.

Leading candidate antigens related to the malaria sexualstage, include P. falciparum Pfs 230 and Pfs48/45, which are expressed by gametocytes, and Pfs 25 , which is exclusively expressed by zygotes and ookinetes. In phase 1 clinical trials, vaccines based on Pfs 25 and its $P$. vivax ortholog Pvs25 have induced antibodies that block mosquito infection (Wu et al., 2008). However, substantial antibody levels were only achieved after four doses, and antibody levels rapidly waned after the final dose (Sagara et al., 2018). In addition, these antigens are cysteine-rich with multiple 6-cys domains and/or epidermal growth factor (EGF)-like domains, and it is difficult to prepare the properly folded recombinant protein (Barr et al., 1991).

The major issue regarding the current subunit malaria vaccines is that they always contain only a single or a small number of antigens, which do not induce broad-spectrum long-lasting immune responses. It is well known that Plasmodium encodes approximately 5,300 proteins, but only a few candidate antigens have been identified (Gardner et al., 2002; Doolan et al., 2003). Therefore, it is currently difficult to design highly efficient subunit malaria vaccines.

\section{PROMISING MALARIA VACCINE: WHOLE-PARASITE BLOOD-STAGE VACCINE}

In contrast to the narrow antigen spectrum related to subunit vaccines, whole-parasite vaccines maximize the spectrum of antigens, greatly enhancing protective immunity, and they have attracted more attention in recent years (Tarun et al., 2008; Ting et al., 2008; Moorthy and Ballou, 2009; Aly et al., 2010; Demarta-Gatsi et al., 2016; Mordmuller et al., 2017; Table 1). Attenuated sporozoites are the most promising vaccines against the pre-erythrocytic stage. It has been reported that either irradiation-, genetic-, or chemo-attenuated sporozoites (also called as chemoprophylaxis with sporozoites, CPS) could induce sterilizing protective immunity against homologous sporozoite challenge in both mice and humans (Nussenzweig et al., 1967; Mueller et al., 2005; Roestenberg et al., 2009; Epstein et al., 2011; Bijker et al., 2013; Seder et al., 2013). An irradiationattenuated sporozoite vaccine could also induce a straintranscending $\mathrm{T}$ cell response and durable protection against heterologous controlled human malaria infection (CHMI; Lyke et al., 2017). PfSPZ vaccine was confirmed to be extremely well tolerated and showed the significant protection in Mali adults against $P$ falciparum infection in phase 1 trial (Sissoko et al., 2017). Furthermore, in the recent study by Roestenberg et al. (2020) in phase $1 / 2 \mathrm{a}$ trial, genetically attenuated malaria vaccine PfSPZ-GA1 also showed the modest protective immunity 
TABLE 1 | The time table of the development of whole parasite vaccines.

\begin{tabular}{|c|c|c|}
\hline $\begin{array}{l}\text { Parasite stage and vaccine } \\
\text { candidate }\end{array}$ & Time & $\begin{array}{l}\text { Current } \\
\text { status }\end{array}$ \\
\hline \multicolumn{3}{|l|}{ Pre-erythrocytic stage } \\
\hline $\begin{array}{l}\text { Radiation-attenuated } \\
\text { sporozoite vaccine (rodent) }\end{array}$ & 1967 (Nussenzweig et al., 1967) & Preclinical \\
\hline $\begin{array}{l}\text { Chemically attenuated } \\
\text { sporozoite vaccine }\end{array}$ & 2009 (Roestenberg et al., 2009) & Phase 2 \\
\hline $\begin{array}{l}\text { Genetically attenuated } \\
\text { sporozoite vaccine }\end{array}$ & 2005 (Mueller et al., 2005) & Phase 1 \\
\hline $\begin{array}{l}\text { Radiation-attenuated } \\
\text { sporozoite vaccine (human) }\end{array}$ & $\begin{array}{l}2011 \text { (Clyde et al., 1973; Clyde, } \\
\text { 1975; Epstein et al., 2011b) }\end{array}$ & Phase 2 \\
\hline \multicolumn{3}{|l|}{ Blood stage } \\
\hline $\begin{array}{l}\text { Whole-killed blood-stage } \\
\text { vaccine }\end{array}$ & 1948 (Freund et al., 1948) & Preclinical \\
\hline $\begin{array}{l}\text { Genetic-attenuated whole- } \\
\text { parasite blood-stage vaccines }\end{array}$ & 2008 (Ting et al., 2008) & Preclinical \\
\hline $\begin{array}{l}\text { Chemically attenuated whole- } \\
\text { parasite blood-stage vaccines }\end{array}$ & 2018 (Stanisic et al., 2018) & Phase 1 \\
\hline
\end{tabular}

Pre-erythrocytic and blood-stage whole parasite vaccines are being evaluated in clinical trials (denoted as phases 1-4) or are being tested in rodent or non-human primate models (preclinical research).

to mosquito-bite challenge. However, safety remains a great concern because the breakthrough of genetically attenuated sporozoites has been reported (Vaughan et al., 2010; Spring et al., 2013). Meanwhile, sporozoites can only be developed in mosquitoes, and sourcing and delivering aseptic, purified, and cryopreserved sporozoites limit the broad application of sporozoite vaccines (Prinz et al., 2018).

Compared to the sourcing of sporozoites, the culture of the Plasmodium falciparum blood stage is a well-established process, so whole-parasite blood-stage vaccines can easily be manufactured. Therefore, efforts have been made to develop genetically or chemically attenuated whole-parasite blood-stage vaccines. Attenuated P. yoelii (Plasmodium yoelii) with purine nucleoside phosphorylase (PNP), nucleoside transporter 1 (NT1), or histamine-releasing factor (HRF) deficiency confer complete sterile protection against both homologous and heterologous blood-stage challenge (Ting et al., 2008; Aly et al., 2010; Demarta-Gatsi et al., 2016). Regarding chemical attenuation, the blood stage can be chemically attenuated both in vivo and in vitro. In vivo, this has been achieved by creating a persistent subpatent blood-stage infection using a low dose of malaria parasite followed by treatment with anti-malaria drugs, which induces sterile protection against both high-dose homologous and heterologous blood-stage challenge (Pombo et al., 2002; Elliott et al., 2005). In vitro, several approaches have been used to chemically attenuate the blood stage, such as treatment with the parasite DNA-binding drugs centanamycin (CM; Good et al., 2013) and tafuramycin-A (TF-A; Stanisic et al., 2018), or the delayed death-causing drugs doxycycline or azithromycin (Low et al., 2019). The vaccination of in vitro chemically attenuated blood stage has also been reported to induce protective immunity against both homologous and heterologous blood-stage challenges (Good et al., 2013; Raja et al., 2016; Low et al., 2019). However, safety concerns regarding the breakthrough of genetically or chemically attenuated blood stages remains unavoidable. In contrast, a $\mathrm{WKV}$, which is an inactive vaccine prepared by several cycles of freezinge/thawing of pRBCs (mostly containing schizonts), is theoretically much safer than other forms of whole-parasite blood-stage vaccine. Furthermore, our previous study and other research have demonstrated that the WKV induced strong protective immunity against both homologous and heterologous blood-stage challenge (Liu et al., 2013; Lu et al., 2017).

Most importantly, the protection brought about by genetically or chemically attenuated blood-stage vaccines involved both antibodies and $\mathrm{CD}^{+} \mathrm{T}$ cell responses (Good et al., 2013; Raja et al., 2016; Low et al., 2019). However, WKV with CpG as the adjuvant is dependent on $\mathrm{CD}^{+} \mathrm{T}$ cell responses, which might target the antigens that are conserved across strains (Pinzon-Charry et al., 2010). Thus, whole-parasite blood-stage vaccines, such as $\mathrm{WKV}$, induce strong $\mathrm{CD}^{+} \mathrm{T}$ cell responses against universal epitopes, allowing them to confer speciestranscending protection, unlike most subunit malaria vaccines against the polymorphic B cell epitopes.

It is thought that a subunit vaccine developed to induce a response against a certain stage of the malaria parasite induces stage-specific, but not cross-stage, immunity. In contrast, wholeparasite vaccines against the pre-erythrocytic stage, such as chemically and genetically attenuated sporozoites, have been shown to induce cross-stage protection against the blood stage (Nahrendorf et al., 2015b; Sack et al., 2015). Although the protection induced by chemically attenuated blood-stage $P$. yoelii parasites was stage specific as immunized mice were not protected against intravenous or mosquito bite sporozoite challenges (Raja et al., 2016), our study showed that the WKV not only conferred the cross-stage immunity against sporozoite challenge but also blocked parasite development in mosquitoes (Figure 2; Lu et al., 2017; Zhu et al., 2017). Therefore, the WKV not only prevents malarial infection and reduces mortality and morbidity among malaria patients but also blocks malaria transmission. Compared to the genetically or chemically attenuated blood-stage vaccines, the $\mathrm{WKV}$ is more acceptable and easily manufactured and shows promise regarding controlling and even eradicating malaria worldwide.

\section{OPTIMIZATION OF THE WKV}

The main limitation of the WKV is the high dose required per vaccine due to its low immunogenicity. The immunization dose of WKV typically needs to be at least $1.5 \times 10^{7}$ parasites or parasite equivalents per vaccine dose (Liu et al., 2013). Therefore, it is a significant challenge due to the difficulties in vaccine manufacture, which involves the human red blood cells. The use of human blood products may also have the possibility to contaminate the vaccine with infectious adventitious agents in the manufacturing process. In the final WKV formulation, an appropriate human-compatible adjuvant is required to induce protection with the lowest dose of parasite. Up to now, all the whole-parasite blood-stage vaccines are at a very early stage of clinical evaluation, and there is no WKV enters clinical trial for the assessment of safety and 


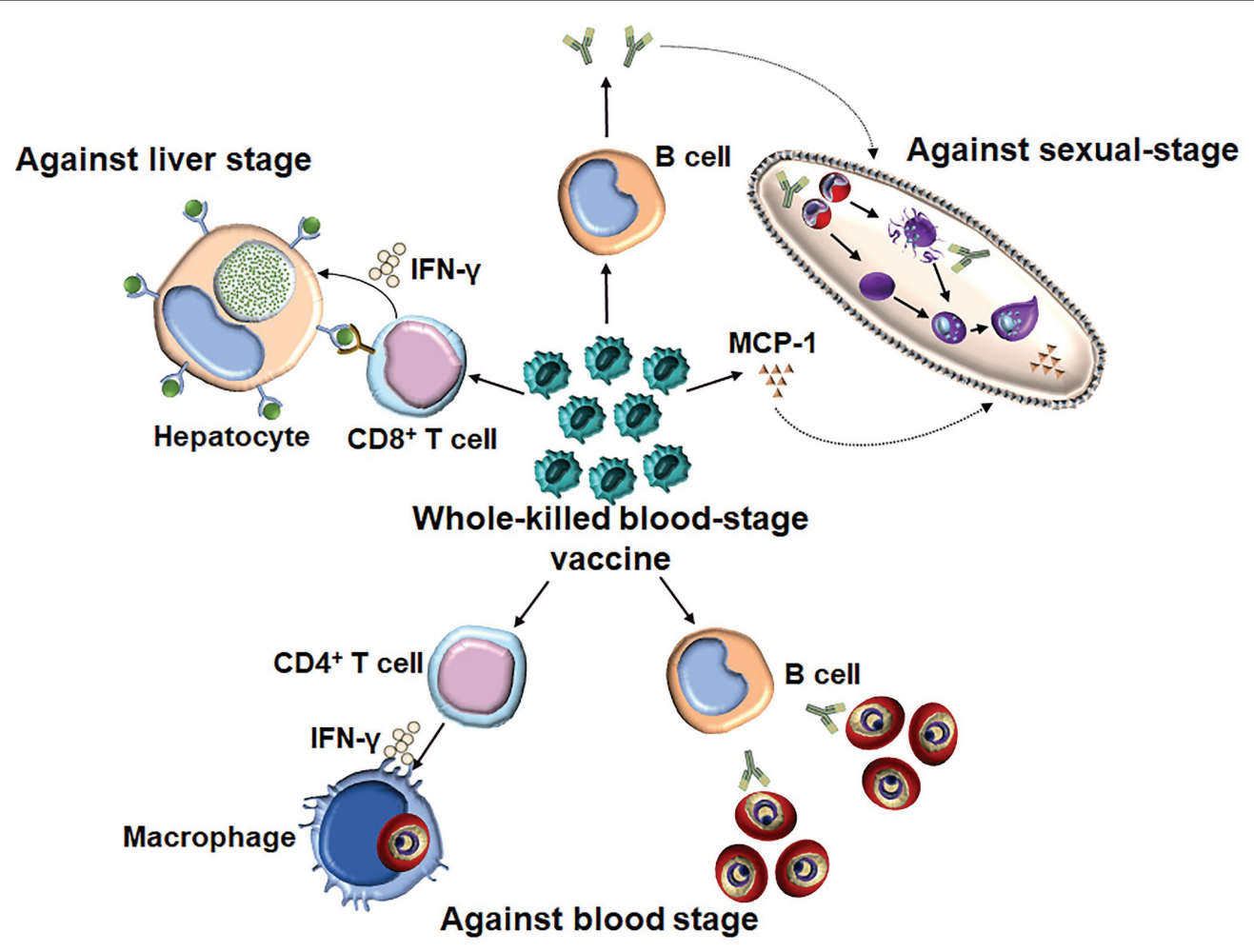

FIGURE 2 | The underlying mechanism of WKV against all three stages. WKV (an inactivate vaccine) could not only efficiently induce a protection against a bloodstage challenge but also confer the cross-stage protection against both liver stage and sexual-stage. The protective immunity against blood stage is dependent on both parasite-specific antibody and CD4 ${ }^{+} \mathrm{T}$ cells, which might enhance the capacity of macrophages to kill the intracellular parasite through the secretion of IFN- $\gamma$. WKV could also provide cross-protection against liver stage through priming parasite-specific $C D 8^{+} T$ cells, although the target antigen of which is still needed to be defined. In contrast, the protective immunity induced by WKV against sexual-stage is largely dependent on parasite-specific antibody and MCP-1, the nonspecific effect of latter might explain the species-transcending protection against sexual-stage.

immunogenicity (Stanisic et al., 2018). Hence, the clinical evaluation of WKV remains a significant challenge. Additionally, the safety concerns regarding the WKV should also be considered, as the parasite is grown in human RBCs, and immunization with pRBCs may induce anti-RBC antibodies and possibly lead to autoimmunity following immunization (Good, 2011). Although no adverse events have been reported, the immunogenicity of the current WKV still needs to be improved. One way to potentially do this is to gain further understanding into the underlying mechanisms of the WKV against each of the three stages, and another is to develop human-compatible adjuvants.

\section{Understanding the Mechanisms of the WKV Against All Three Stages}

Knowledge of the mechanisms of the WKV against all stages would guide the optimization of its formulation. Regarding the protective immunity induced by the WKV against the blood stage, several studies have demonstrated that it is dependent on both humoral and $\mathrm{CD}^{+} \mathrm{T}$ cell responses (PinzonCharry et al., 2010). Although the purine salvage enzyme HGXPT (hypoxanthine guanine xanthine phosphoribosyl transferase) has been identified as a major potential target antigen for $\mathrm{CD}^{+} \mathrm{T}$ cell responses against the blood stage
(Makobongo et al., 2003; Woodberry et al., 2009), the protective $B$ cell antigens of WKV still need to be defined. We found that the WKV could greatly increase the frequency of $\mathrm{CD} 8 \alpha^{\text {low }} \mathrm{CD} 11 \mathrm{a}^{\text {high }} \mathrm{T}$ cells, which are representative malaria parasite-specific $\mathrm{CD}^{+} \mathrm{T}$ cells (Rai et al., 2009). A T cell depletion assay demonstrated that the protective immunity induced by the WKV against the liver stage is mainly dependent on $\mathrm{CD}^{+} \mathrm{T}$ cell responses, but not $\mathrm{CD}^{+} \mathrm{T}$ cell responses (Lu et al., 2017). Cytotoxic $\mathrm{CD}^{+} \mathrm{T}$ cells were previously thought to have no role against the blood stages because RBCs generally do not express human leukocyte antigen class I (HLA I). However, a recent study showed that P. vivaxinfected reticulocytes express HLA I and circulating $\mathrm{CD}^{+} \mathrm{T}$ cells in malaria patients can recognize the $P$. vivax-infected reticulocytes in a HLA-dependent manner and kill the intracellular parasites (Junqueira et al., 2018). Despite this, the relative importance of the role of parasite-specific $\mathrm{CD}^{+}$ $\mathrm{T}$ cells regarding the protective immunity induced by the WKV against the Plasmodium, which cannot infect reticulocytes, remains unclear. In contrast to protective immunity against the blood and liver stages, we found that $\mathrm{CD}^{+} \mathrm{T}$ effector cells are dispensable for the cross-protection induced by the WKV against the sexual-stage (Zhu et al., 2017). Instead, this cross-protection is mainly dependent on malaria parasite-specific 
antibodies and monocyte chemoattractant protein (MCP)-1, but not interferon (IFN)- $\gamma$ (Zhu et al., 2017). Although the exact mechanism of MCP-1 against the sexual-stage in this context is unknown, its non-specific effect might interpret the cross-species protection induced by the WKV against sexual-stage.

Interestingly, the cellular and humoral immune responses induced by the WKV are critical for its cross-protection against the liver and sexual-stage, respectively (Liu et al., 2013; Lu et al., 2017). Therefore, the investigation of underlying mechanisms for the activation of cellular and humoral immune responses may help us to optimize the WKV against all stages. It has been shown that the activation of malaria parasitespecific immune responses during WKV immunization involves malarial hemozoin triggering TLR9 (Toll-like receptor 9; Coban et al., 2010). Our previous data also indicated that the C5a/ C5aR signaling pathway in dendritic cells (DCs) was activated during immunization and is essential for the optimal induction of the malaria parasite-specific $\mathrm{CD} 4^{+} \mathrm{T}$ cell response (Liu et al., 2013). However, the investigation of the critical components of the WKV responsible for the upregulation of protective immune responses has only just begun.

In addition to the positive regulatory components, the identification and genetic deletion of the components that negatively regulate the protective immune response is also critical for vaccine optimization. In humans, the malaria parasite induces DC apoptosis and thereby inhibits parasite-specific $\mathrm{CD}^{+} \mathrm{T}$ cell responses to facilitate its survival (Woodberry et al., 2012; Pinzon-Charry et al., 2013), along with downregulating costimulatory molecules on DCs (Urban et al., 1999). Additionally, $\operatorname{Tr} 27$ cells, which are IL-27-producing CD4 ${ }^{+}$ $\mathrm{T}$ cells, are induced by the malaria parasite to regulate $\mathrm{CD} 4^{+}$ $\mathrm{T}$ cell responses against the infection (Kimura et al., 2016). The expansion of $\mathrm{CD} 4^{+} \mathrm{CD} 25^{+}$regulatory $\mathrm{T}$ cells during malaria infection suppresses $\mathrm{T}$ helper cell responses and follicular $\mathrm{T}$ helper (TFH)-B cell interactions in germinal centers via secretion of CTLA-4 (Figure 3; Kurup et al., 2017). This has been confirmed by the findings that the protection efficacy induced by several whole-parasite vaccines is much lower in malariaexposed African individuals than in malaria-naïve United States and European individuals, and the malaria blood stage infection also suppresses both the humoral and cellular immune responses against sporozoites (Ocana-Morgner et al., 2003; Keitany et al., 2016). Furthermore, durable immunity was also difficult to be induced in African individuals, potentially because malaria inhibits the vaccine-induced formation of long-lived plasma cells (LLPCs) and high-affinity memory B cells (MBCs). Multiple mechanisms have been postulated to explain the insufficient induction of LLPCs and MBCs, including preferential expansion of CXCR3 $^{+}$(TH1-like) TFH cells (Obeng-Adjei et al., 2015), regulatory $\mathrm{T}$ cells (Kurup et al., 2017), and atypical MBCs (Weiss et al., 2009; Obeng-Adjei et al., 2017), as well as the dysregulation of chemokines and cytokines (Ryg-Cornejo et al., 2016) and the induction of immune checkpoints (Butler et al., 2011), which may delay or impair the acquisition of humoral immunity against malaria. In addition, a recent study revealed that the metabolic hyperactivity of plasmablasts resulted in nutrient deprivation that affects the germinal center reaction, limiting the generation of MBC and LLPC responses against malaria parasites (Vijay et al., 2020). The limited duration of the host protective immunity against the malaria parasite may also be explained by the parasite, inducing the apoptosis of LLPCs, MBCs, and activated $\mathrm{CD}^{+}{ }^{+} \mathrm{T}$ cells (Figure 3; Hirunpetcharat and Good, 1998; Wipasa et al., 2001; Xu et al., 2002; Wykes et al., 2005). Lastly, the immune evasion mechanisms established by the malaria blood stage also include the parasite antigen variation, sequestration, and rosetting (Niang et al., 2014; Wahlgren et al., 2017; Belachew, 2018).

The identification of cross-protective antigens shared by all three stages could also help to optimize the multi-stage effects of the WKV and facilitate the development of a multi-stage malaria subunit vaccine. Several recent studies have reported cross-stage protection between the blood and liver stages (Nahrendorf et al., 2015b; Sack et al., 2015), and the identification of cross-protective antigens has attracted more attention (Nahrendorf et al., 2015a). Although no cross-protective antigens have yet been identified, it should be feasible to screen for the overlapping antigens by comparing the transcriptional profiles between two stages. Additionally, the proteome-wide screening of antibody and $\mathrm{T}$ cell reactivity between protected and unprotected individuals (immunomics) may also help to characterize the cross-protective antigens (Doolan, 2011; Davies et al., 2015; Schussek et al., 2017). Concurrently, further research is needed on WKV components that may downregulate host protective immune responses.

\section{Development of an Appropriate Human-Compatible Adjuvant}

Developing an appropriate human-compatible adjuvant to enhance the immunogenicity of the WKV is an urgent issue. Aluminum-containing adjuvants are the most widely used clinical adjuvants, which have been demonstrated not only to directly trigger the NALP3 inflammasome but also to indirectly activate the host innate immune response by inducing the release of the endogenous danger signal uric acid (Lambrecht et al., 2009). However, we found that alum only slightly improved the immunogenicity of pRBC lysate (Fu et al., 2020). Although CPG has been reported to be able to significantly enhance the malaria parasite-specific $\mathrm{CD} 4^{+} \mathrm{T}$ responses and reduce the vaccine dose from $10^{8}$ to $10^{3}$ (Pinzon-Charry et al., 2010), the use of $\mathrm{CpG}$ as an adjuvant in humans has not been approved.

The immunomodulatory role of chloroquine has been known for approximately 30 years. Early ex vivo studies claimed that chloroquine had a direct suppressive effect on several immune cells, such as T cells and natural killer cells (Bygbjerg et al., 1986, 1987; Goldman et al., 2000). However, chloroquine was found to greatly promote $\mathrm{CD} 8^{+} \mathrm{T}$ cell responses against soluble antigens in vivo, through inhibiting the degradation of internalized soluble antigen in endosomes by increasing the $\mathrm{pH}$ of the endosomes (Accapezzato et al., 2005). Interestingly, we found that low-dose antimalarial chloroquine along with alum synergistically improved the immunogenicity of $\mathrm{pRBC}$ lysates by enhancing the humoral response, although 


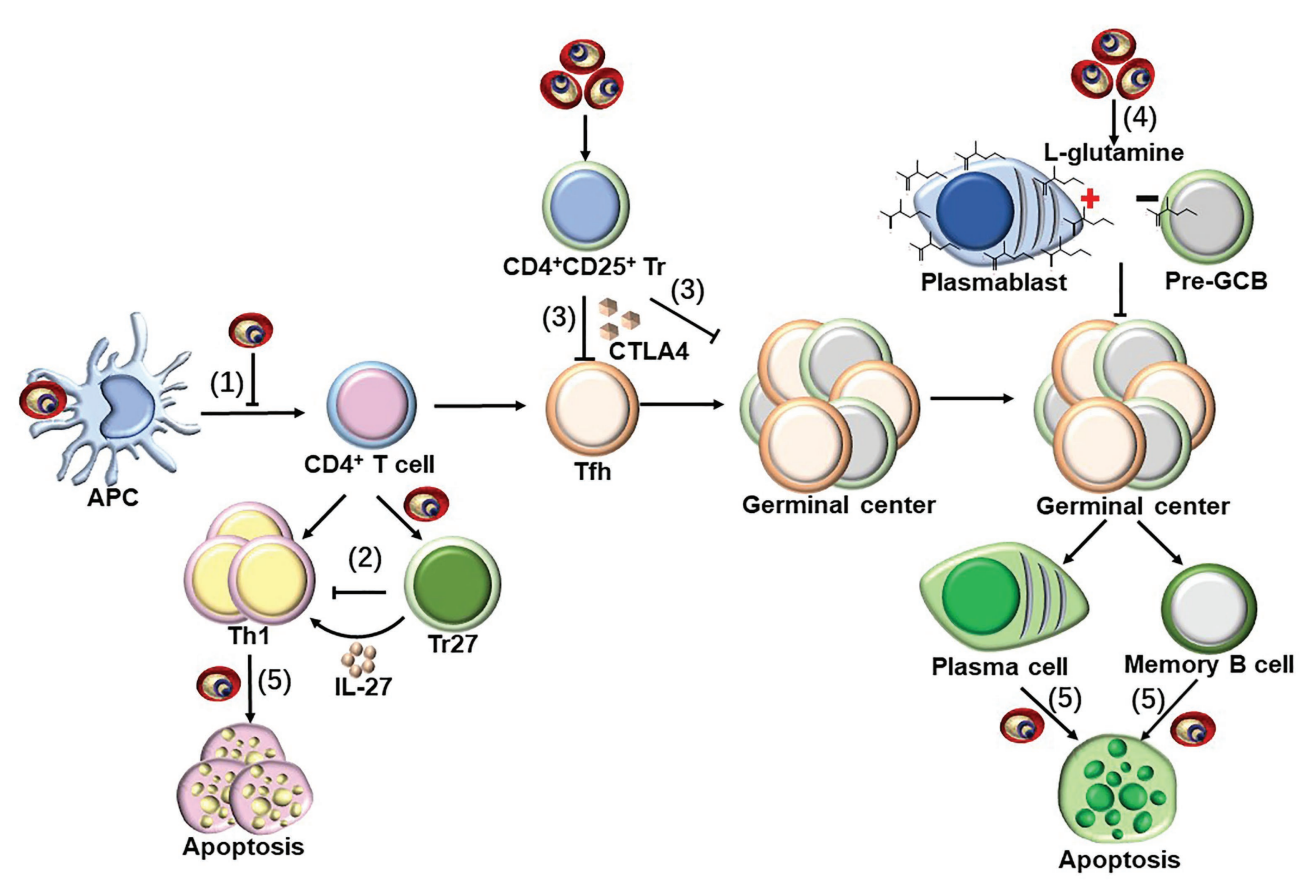

FIGURE 3 | Strategies to suppress host immune response by blood-stage malaria parasites. Parasite-specific CD4+ ${ }^{+}$cells are essential for host protective immunity against blood stage, as which can not only directly clear parasite through secretion Th1 cytokines but also provide help for B cells to produce antibody. However, malaria parasites have evolved to evade host immune response through following strategies. (1) pRBCs could inhibit the maturation of DCs, and subsequently suppress the CD4+ T cell activation (Urban et al., 1999; Woodberry et al., 2012; Pinzon-Charry et al., 2013). (2) Tr27 cells, the IL-27-producing CD4+ T cells, have also been reported to be activated during malaria infection, which reciprocally suppresses CD4 ${ }^{+} \mathrm{T}$ cells activation through the secretion of IL-27 (Kimura et al., 2016). (3) Malaria infection also induce the expansion of CD4+CD25+ regulatory $\mathrm{T}$ cells, which interfere $\mathrm{T}$ helper cell responses and follicular $\mathrm{T}$ helper (TFH)-B cell interactions in germinal centers through secretion of CTLA-4 (Kurup et al., 2017). (4) The early differentiation of parasite-specific B cells into short-lived plasmablasts consumes a large amount of L-glutamine during malaria blood-stage infection, resulting in the nutrient deprivation of GCB, limiting the generation of $\mathrm{MBC}$ and LLPC responses against malaria parasites (Vijay et al., 2020). (5) The infection of malaria parasite could even induce the apoptosis of the activated CD4+ $T$ cells dependent on IFN- $\gamma$, but both LLPCs and MBCs are deleted by an unknown mechanism (Hirunpetcharat and Good, 1998; Wipasa et al., 2001; Xu et al., 2002; Wykes et al., 2005).

chloroquine alone only had a slight effect (Fu et al., 2020). As chloroquine has been approved as safe for humans, we strongly suggest that the use of low-dose chloroquine, along with alum, should be explored to enhance the immunogenicity of WKV.

\section{CONCLUDING REMARKS AND FUTURE PERSPECTIVES}

Although the burden of malaria has been greatly reduced by control measures in the past decades, a highly efficient and safe vaccine is a high priority to ultimately control and even eradicate malaria around the world. Plasmodium is a complicated organism, encoding more than 5,000 proteins, but only a few protective antigens have been identified. Therefore, the current subunit vaccine strategy has encountered major challenges, as these vaccines can only induce narrow immune responses, and the future development of malaria subunit vaccine is not optimistic. Although multi-stage or multi-antigen vaccines are theoretically promising to control malaria, it is dependent on the identification of protective antigens. In contrast, the immune responses induced by whole-parasite vaccines are broad, sparking a renewed interest in these vaccines. Owing to the difficulties in sourcing and delivering cryopreserved sporozoites, whole-parasite bloodstage vaccine manufacturing is more feasible, as the culture of $P$. falciparum blood stage is a well-established process. Furthermore, the Plasmodium life cycle is very complicated, with three developmental stages, each of which has different antigens. An ideal vaccine would confer cross-stage immunity against all three stages, and WKV, an inactive whole-parasite vaccine, is safe and can induce cross-protection against both the liver and sexual-stages.

However, the immunogenicity of WKV is low and needs to be improved. To optimize WKV, two major elements should be identified: (1) malaria parasite components that positively regulate the host immune responses and (2) the mechanisms and parasite components that suppress or evade the host immune responses, which would affect the magnitude and duration of the protective immune response induced by WKV. With this knowledge, negative regulatory components could be removed and positively components could be strengthened from the parasite by genetic manipulation to greatly improve the immunogenicity and protective efficacy of the WKV. 


\section{AUTHOR CONTRIBUTIONS}

WX and TL: conceptualization, writing-review and editing, and funding acquisition. JC, SC, XL, and FZ: writing-original draft. All authors contributed to the article and approved the submitted version.

\section{REFERENCES}

Accapezzato, D., Visco, V., Francavilla, V., Molette, C., Donato, T., Paroli, M., et al. (2005). Chloroquine enhances human $\mathrm{CD}^{+} \mathrm{T}$ cell responses against soluble antigens in vivo. J. Exp. Med. 202, 817-828. doi: 10.1084/jem.20051106

Acquah, F. K., Adjah, J., Williamson, K. C., and Amoah, L. E. (2019). Transmissionblocking vaccines: old friends and new prospects. Infect. Immun. 87, e00775-e00818. doi: 10.1128/IAI.00775-18

Agnandji, S. T., Lell, B., Fernandes, J. F., Abossolo, B. P., Methogo, B. G., Kabwende, A. L., et al. (2012). A phase 3 trial of RTS,S/AS01 malaria vaccine in African infants. N. Engl. J. Med. 367, 2284-2295. doi: 10.1056/ NEJMoa1208394

Agnandji, S. T., Lell, B., Soulanoudjingar, S. S., Fernandes, J. F., Abossolo, B. P., Conzelmann, C., et al. (2011). First results of phase 3 trial of RTS,S/AS01 malaria vaccine in African children. N. Engl. J. Med. 365, 1863-1875. doi: 10.1056/NEJMoa1102287

Alanine, D. G. W., Quinkert, D., Kumarasingha, R., Mehmood, S., Donnellan, F. R., Minkah, N. K., et al. (2019). Human antibodies that slow erythrocyte invasion potentiate malaria-neutralizing antibodies. Cell 178, 216.e221-228.e221. doi: 10.1016/j.cell.2019.05.025

Aly, A. S., Downie, M. J., Mamoun, C. B., and Kappe, S. H. (2010). Subpatent infection with nucleoside transporter 1-deficient Plasmodium blood stage parasites confers sterile protection against lethal malaria in mice. Cell. Microbiol. 12, 930-938. doi: 10.1111/j.1462-5822.2010.01441.x

Barr, P. J., Green, K. M., Gibson, H. L., Bathurst, I. C., Quakyi, I. A., and Kaslow, D. C. (1991). Recombinant Pfs 25 protein of Plasmodium falciparum elicits malaria transmission-blocking immunity in experimental animals. J. Exp. Med. 174, 1203-1208. doi: 10.1084/jem.174.5.1203

Belachew, E. B. (2018). Immune response and evasion mechanisms of Plasmodium falciparum parasites. J. Immunol. Res. 2018:6529681. doi: 10.1155/2018/ 6529681

Bijker, E. M., Bastiaens, G. J., Teirlinck, A. C., van Gemert, G. J., Graumans, W., van de Vegte-Bolmer, M., et al. (2013). Protection against malaria after immunization by chloroquine prophylaxis and sporozoites is mediated by preerythrocytic immunity. Proc. Natl. Acad. Sci. U. S. A. 110, 7862-7867. doi: $10.1073 /$ pnas. 1220360110

Bull, P. C., Lowe, B. S., Kortok, M., Molyneux, C. S., Newbold, C. I., and Marsh, K. (1998). Parasite antigens on the infected red cell surface are targets for naturally acquired immunity to malaria. Nat. Med. 4, 358-360. doi: $10.1038 / \mathrm{nm} 0398-358$

Butler, N. S., Moebius, J., Pewe, L. L., Traore, B., Doumbo, O. K., Tygrett, L. T., et al. (2011). Therapeutic blockade of PD-L1 and LAG-3 rapidly clears established blood-stage Plasmodium infection. Nat. Immunol. 13, 188-195. doi: 10.1038/ni.2180

Bygbjerg, I. C., Svenson, M., Theander, T. G., and Bendtzen, K. (1987). Effect of antimalarial drugs on stimulation and interleukin 2 production of human lymphocytes. Int. J. Immunopharmacol. 9, 513-519. doi: 10.1016/01920561(87)90027-0

Bygbjerg, I. C., Theander, T. G., Andersen, B. J., Flachs, H., Jepsen, S., and Larsen, P. B. (1986). In vitro effect of chloroquine, mefloquine and quinine on human lymphocyte proliferative responses to malaria antigens and other antigens/mitogens. Trop. Med. Parasitol. 37, 245-247.

Casares, S., Brumeanu, T. D., and Richie, T. L. (2010). The RTS,S malaria vaccine. Vaccine 28, 4880-4894. doi: 10.1016/j.vaccine.2010.05.033

Clyde, D. F. (1975). Immunization of man against falciparum and vivax malaria by use of attenuated sporozoites. Am. J. Trop. Med. Hyg. 24, 397-401. doi: 10.4269/ajtmh.1975.24.397

Clyde, D. F., McCarthy, V. C., Miller, R. M., and Hornick, R. B. (1973). Specificity of protection of man immunized against sporozoite-induced falciparum malaria. Am. J. Med. Sci. 266, 398-403. doi: 10.1097/00000441-197312000-00001

\section{FUNDING}

This work was supported by the State Key Program of the National Natural Science Foundation of China (Nos. 81830067 and 82072299).

Coban, C., Igari, Y., Yagi, M., Reimer, T., Koyama, S., Aoshi, T., et al. (2010). Immunogenicity of whole-parasite vaccines against Plasmodium falciparum involves malarial hemozoin and host TLR9. Cell Host Microbe 7, 50-61. doi: 10.1016/j.chom.2009.12.003

Cohen, J. (1996). Vaccine Composition Against Malaria. U.S. patent.

Crompton, P. D., Pierce, S. K., and Miller, L. H. (2010). Advances and challenges in malaria vaccine development. J. Clin. Invest. 120, 4168-4178. doi: 10.1172/ JCI44423

Dame, J. B., Williams, J. L., McCutchan, T. F., Weber, J. L., Wirtz, R. A., Hockmeyer, W. T., et al. (1984). Structure of the gene encoding the immunodominant surface antigen on the sporozoite of the human malaria parasite Plasmodium falciparum. Science 225, 593-599. doi: 10.1126/ science. 6204383

Davies, D. H., Duffy, P., Bodmer, J. L., Felgner, P. L., and Doolan, D. L. (2015). Large screen approaches to identify novel malaria vaccine candidates. Vaccine 33, 7496-7505. doi: 10.1016/j.vaccine.2015.09.059

Demarta-Gatsi, C., Smith, L., Thiberge, S., Peronet, R., Commere, P. H., Matondo, M., et al. (2016). Protection against malaria in mice is induced by blood stage-arresting histamine-releasing factor (HRF)-deficient parasites. J. Exp. Med. 213, 1419-1428. doi: 10.1084/jem.20151976

Doolan, D. L. (2011). Plasmodium immunomics. Int. J. Parasitol. 41, 3-20. doi: 10.1016/j.ijpara.2010.08.002

Doolan, D. L., Southwood, S., Freilich, D. A., Sidney, J., Graber, N. L., Shatney, L., et al. (2003). Identification of Plasmodium falciparum antigens by antigenic analysis of genomic and proteomic data. Proc. Natl. Acad. Sci. U. S. A. 100, 9952-9957. doi: 10.1073/pnas.1633254100

Douglas, A. D., Baldeviano, G. C., Lucas, C. M., Lugo-Roman, L. A., Crosnier, C., Bartholdson, S. J., et al. (2015). A PfRH5-based vaccine is efficacious against heterologous strain blood-stage Plasmodium falciparum infection in aotus monkeys. Cell Host Microbe 17, 130-139. doi: 10.1016/j.chom.2014. 11.017

Douglas, A. D., Williams, A. R., Illingworth, J. J., Kamuyu, G., Biswas, S., Goodman, A. L., et al. (2011). The blood-stage malaria antigen PfRH5 is susceptible to vaccine-inducible cross-strain neutralizing antibody. Nat. Commun. 2:601. doi: 10.1038/ncomms1615

Elliott, S. R., Kuns, R. D., and Good, M. F. (2005). Heterologous immunity in the absence of variant-specific antibodies after exposure to subpatent infection with blood-stage malaria. Infect. Immun. 73, 2478-2485. doi: 10.1128/ IAI.73.4.2478-2485.2005

EMA (2015). First Malaria Vaccine Receives Positive Scientific Opinion From EMA. Available at: https://www.ema.europa.eu/en/news/first-malaria-vaccinereceives-positive-scientificopinion-ema (Accessed January 10, 2021).

Epstein, J. E., Tewari, K., Lyke, K. E., Sim, B. K., Billingsley, P. F., Laurens, M. B., et al. (2011). Live attenuated malaria vaccine designed to protect through hepatic CD8 T cell immunity. Science 334, 475-480. doi: 10.1126/science. 1211548

Fowkes, F. J., Richards, J. S., Simpson, J. A., and Beeson, J. G. (2010). The relationship between anti-merozoite antibodies and incidence of Plasmodium falciparum malaria: a systematic review and meta-analysis. PLoS Med. 7:e1000218. doi: 10.1371/journal.pmed.1000218

Freund, J., Thomson, K. J., Sommer, H. E., Walter, A. W., and Pisani, T. M. (1948). Immunization of monkeys against malaria by means of killed parasites with adjuvants. Am. J. Trop. Med. Hyg. 28, 1-22. doi: 10.4269/ajtmh.1948. s1-28.1

Fu, Y., Lu, X., Zhu, F., Zhao, Y., Ding, Y., Ye, L., et al. (2020). Improving the immunogenicity and protective efficacy of a whole-killed malaria blood-stage vaccine by chloroquine. Parasite Immunol. 42:e12682. doi: 10.1111/pim.12682

Gardner, M. J., Hall, N., Fung, E., White, O., Berriman, M., Hyman, R. W., et al. (2002). Genome sequence of the human malaria parasite Plasmodium falciparum. Nature 419, 498-511. doi: 10.1038/nature01097 
Goldman, F. D., Gilman, A. L., Hollenback, C., Kato, R. M., Premack, B. A., and Rawlings, D. J. (2000). Hydroxychloroquine inhibits calcium signals in T cells: a new mechanism to explain its immunomodulatory properties. Blood 95, 3460-3466. doi: 10.1182/blood.V95.11.3460

Good, M. F. (2011). A whole parasite vaccine to control the blood stages of Plasmodium-the case for lateral thinking. Trends Parasitol. 27, 335-340. doi: 10.1016/j.pt.2011.03.003

Good, M. F., Reiman, J. M., Rodriguez, I. B., Ito, K., Yanow, S. K., El-Deeb, I. M., et al. (2013). Cross-species malaria immunity induced by chemically attenuated parasites. J. Clin. Invest. 123, 3353-3362. doi: 10.1172/JCI66634

Hirunpetcharat, C., and Good, M. F. (1998). Deletion of Plasmodium bergheispecific $\mathrm{CD} 4^{+} \mathrm{T}$ cells adoptively transferred into recipient mice after challenge with homologous parasite. Proc. Natl. Acad. Sci. U. S. A. 95, 1715-1720. doi: $10.1073 /$ pnas. 95.4 .1715

Julien, J. P., and Wardemann, H. (2019). Antibodies against Plasmodium falciparum malaria at the molecular level. Nat. Rev. Immunol. 19, 761-775. doi: 10.1038/ s41577-019-0209-5

Junqueira, C., Barbosa, C. R. R., Costa, P. A. C., Teixeira-Carvalho, A., Castro, G., Sen Santara, S., et al. (2018). Cytotoxic CD8(+) T cells recognize and kill Plasmodium vivax-infected reticulocytes. Nat. Med. 24, 1330-1336. doi: 10.1038/s41591-018-0117-4

Keitany, G. J., Kim, K. S., Krishnamurty, A. T., Hondowicz, B. D., Hahn, W. O., Dambrauskas, N., et al. (2016). Blood stage malaria disrupts humoral immunity to the pre-erythrocytic stage circumsporozoite protein. Cell Rep. 17, 3193-3205. doi: 10.1016/j.celrep.2016.11.060

Kimura, D., Miyakoda, M., Kimura, K., Honma, K., Hara, H., Yoshida, H., et al. (2016). Interleukin-27-producing $\mathrm{CD} 4(+) \mathrm{T}$ cells regulate protective immunity during malaria parasite infection. Immunity 44, 672-682. doi: 10.1016/j.immuni.2016.02.011

Kumar, K. A., Sano, G., Boscardin, S., Nussenzweig, R. S., Nussenzweig, M. C., Zavala, F., et al. (2006). The circumsporozoite protein is an immunodominant protective antigen in irradiated sporozoites. Nature 444, 937-940. doi: 10.1038/ nature05361

Kurup, S. P., Obeng-Adjei, N., Anthony, S. M., Traore, B., Doumbo, O. K., Butler, N. S., et al. (2017). Regulatory T cells impede acute and long-term immunity to blood-stage malaria through CTLA-4. Nat. Med. 23, 1220-1225. doi: $10.1038 / \mathrm{nm} .4395$

Lambrecht, B. N., Kool, M., Willart, M. A., and Hammad, H. (2009). Mechanism of action of clinically approved adjuvants. Curr. Opin. Immunol. 21, 23-29. doi: 10.1016/j.coi.2009.01.004

Liu, T., Xu, G., Guo, B., Fu, Y., Qiu, Y., Ding, Y., et al. (2013). An essential role for $\mathrm{C} 5 \mathrm{aR}$ signaling in the optimal induction of a malaria-specific $\mathrm{CD} 4^{+}$ $\mathrm{T}$ cell response by a whole-killed blood-stage vaccine. J. Immunol. 191, 178-186. doi: 10.4049/jimmunol.1201190

Low, L. M., Ssemaganda, A., Liu, X. Q., Ho, M. F., Ozberk, V., Fink, J., et al. (2019). Controlled infection immunization using delayed death drug treatment elicits protective immune responses to blood-stage malaria parasites. Infect. Immun. 87, e00587-e00618. doi: 10.1128/IAI.00587-18

Lu, X., Liu, T., Zhu, F., Chen, L., and Xu, W. (2017). A whole-killed, bloodstage lysate vaccine protects against the malaria liver stage. Parasite Immunol. 39:e12386. doi: 10.1111/pim.12386

Lyke, K. E., Ishizuka, A. S., Berry, A. A., Chakravarty, S., DeZure, A., Enama, M. E., et al. (2017). Attenuated PfSPZ vaccine induces strain-transcending $\mathrm{T}$ cells and durable protection against heterologous controlled human malaria infection. Proc. Natl. Acad. Sci. U. S. A. 114, 2711-2716. doi: 10.1073/pnas.1615324114

Makobongo, M. O., Riding, G., Xu, H., Hirunpetcharat, C., Keough, D., de Jersey, J., et al. (2003). The purine salvage enzyme hypoxanthine guanine xanthine phosphoribosyl transferase is a major target antigen for cell-mediated immunity to malaria. Proc. Natl. Acad. Sci. U. S. A. 100, 2628-2633. doi: 10.1073/pnas.0337629100

Moorthy, V. S., and Ballou, W. R. (2009). Immunological mechanisms underlying protection mediated by RTS,S: a review of the available data. Malar. J. 8:312. doi: 10.1186/1475-2875-8-312

Mordmuller, B., Surat, G., Lagler, H., Chakravarty, S., Ishizuka, A. S., Lalremruata, A., et al. (2017). Sterile protection against human malaria by chemoattenuated PfSPZ vaccine. Nature 542, 445-449. doi: 10.1038/nature21060

Mueller, A. K., Labaied, M., Kappe, S. H., and Matuschewski, K. (2005). Genetically modified Plasmodium parasites as a protective experimental malaria vaccine. Nature 433, 164-167. doi: 10.1038/nature03188
Nahrendorf, W., Scholzen, A., Sauerwein, R. W., and Langhorne, J. (2015a). Cross-stage immunity for malaria vaccine development. Vaccine 33, 7513-7517. doi: 10.1016/j.vaccine.2015.09.098

Nahrendorf, W., Spence, P. J., Tumwine, I., Levy, P., Jarra, W., Sauerwein, R. W., et al. (2015b). Blood-stage immunity to Plasmodium chabaudi malaria following chemoprophylaxis and sporozoite immunization. eLife 4:e05165. doi: $10.7554 /$ eLife.05165

Niang, M., Bei, A. K., Madnani, K. G., Pelly, S., Dankwa, S., Kanjee, U., et al. (2014). STEVOR is a Plasmodium falciparum erythrocyte binding protein that mediates merozoite invasion and rosetting. Cell Host Microbe 16, 81-93. doi: 10.1016/j.chom.2014.06.004

Nussenzweig, R. S., Vanderberg, J., Most, H., and Orton, C. (1967). Protective immunity produced by the injection of $\mathrm{x}$-irradiated sporozoites of Plasmodium berghei. Nature 216, 160-162. doi: 10.1038/216160a0

Obeng-Adjei, N., Portugal, S., Holla, P., Li, S., Sohn, H., Ambegaonkar, A., et al. (2017). Malaria-induced interferon-gamma drives the expansion of Tbethi atypical memory B cells. PLoS Pathog. 13:e1006576. doi: 10.1371/ journal.ppat.1006576

Obeng-Adjei, N., Portugal, S., Tran, T. M., Yazew, T. B., Skinner, J., Li, S., et al. (2015). Circulating Th1-cell-type Th cells that exhibit impaired B cell help are preferentially activated during acute malaria in children. Cell Rep. 13, 425-439. doi: 10.1016/j.celrep.2015.09.004

Ocana-Morgner, C., Mota, M. M., and Rodriguez, A. (2003). Malaria blood stage suppression of liver stage immunity by dendritic cells. J. Exp. Med. 197, 143-151. doi: 10.1084/jem.20021072

Ogutu, B. R., Apollo, O. J., McKinney, D., Okoth, W., Siangla, J., Dubovsky, F., et al. (2009). Blood stage malaria vaccine eliciting high antigen-specific antibody concentrations confers no protection to young children in Western Kenya. PLoS One 4:e4708. doi: 10.1371/journal.pone.0004708

O’Meara, W. P., Mangeni, J. N., Steketee, R., and Greenwood, B. (2010). Changes in the burden of malaria in sub-Saharan Africa. Lancet Infect. Dis. 10, 545-555. doi: 10.1016/S1473-3099(10)70096-7

Phyo, A. P., Nkhoma, S., Stepniewska, K., Ashley, E. A., Nair, S., McGready, R., et al. (2012). Emergence of artemisinin-resistant malaria on the western border of Thailand: a longitudinal study. Lancet 379, 1960-1966. doi: 10.1016/ S0140-6736(12)60484-X

Pinzon-Charry, A., McPhun, V., Kienzle, V., Hirunpetcharat, C., Engwerda, C., McCarthy, J., et al. (2010). Low doses of killed parasite in CpG elicit vigorous $\mathrm{CD}^{+} \mathrm{T}$ cell responses against blood-stage malaria in mice. J. Clin. Invest. 120, 2967-2978. doi: 10.1172/JCI39222

Pinzon-Charry, A., Woodberry, T., Kienzle, V., McPhun, V., Minigo, G., Lampah, D. A., et al. (2013). Apoptosis and dysfunction of blood dendritic cells in patients with falciparum and vivax malaria. J. Exp. Med. 210, 1635-1646. doi: 10.1084/jem.20121972

Pombo, D. J., Lawrence, G., Hirunpetcharat, C., Rzepczyk, C., Bryden, M., Cloonan, N., et al. (2002). Immunity to malaria after administration of ultra-low doses of red cells infected with Plasmodium falciparum. Lancet 360, 610-617. doi: 10.1016/S0140-6736(02)09784-2

Prinz, H., Sattler, J. M., Roth, A., Ripp, J., Adams, J. H., and Frischknecht, F. (2018). Immunization efficacy of cryopreserved genetically attenuated Plasmodium berghei sporozoites. Parasitol. Res. 117, 2487-2497. doi: 10.1007/s00436-018-5937-0

Rai, D., Pham, N. L., Harty, J. T., and Badovinac, V. P. (2009). Tracking the total CD8 $\mathrm{T}$ cell response to infection reveals substantial discordance in magnitude and kinetics between inbred and outbred hosts. J. Immunol. 183, 7672-7681. doi: 10.4049/jimmunol.0902874

Raja, A. I., Cai, Y., Reiman, J. M., Groves, P., Chakravarty, S., McPhun, V., et al. (2016). Chemically attenuated blood-stage Plasmodium yoelii parasites induce long-lived and strain-transcending protection. Infect. Immun. 84, 2274-2288. doi: 10.1128/IAI.00157-16

Ranson, H., N'Guessan, R., Lines, J., Moiroux, N., Nkuni, Z., and Corbel, V. (2011). Pyrethroid resistance in African anopheline mosquitoes: what are the implications for malaria control? Trends Parasitol. 27, 91-98. doi: 10.1016/j. pt.2010.08.004

Rathore, D., Sacci, J. B., de la Vega, P., and McCutchan, T. F. (2002). Binding and invasion of liver cells by Plasmodium falciparum sporozoites. Essential involvement of the amino terminus of circumsporozoite protein. J. Biol. Chem. 277, 7092-7098. doi: 10.1074/jbc.M106862200

Roestenberg, M., McCall, M., Hopman, J., Wiersma, J., Luty, A. J., van Gemert, G. J., et al. (2009). Protection against a malaria challenge by 
sporozoite inoculation. N. Engl. J. Med. 361, 468-477. doi: 10.1056/ NEJMoa0805832

Roestenberg, M., Walk, J., van der Boor, S. C., Langenberg, M. C. C., Hoogerwerf, M. A., Janse, J. J., et al. (2020). A double-blind, placebocontrolled phase $1 / 2 \mathrm{a}$ trial of the genetically attenuated malaria vaccine PfSPZ-GA1. Sci. Transl. Med. 12:eaaz5629. doi: 10.1126/scitranslmed.aaz5629

Rts, S. C. T. P. (2015). Efficacy and safety of RTS,S/AS01 malaria vaccine with or without a booster dose in infants and children in Africa: final results of a phase 3, individually randomised, controlled trial. Lancet 386, 31-45. doi: 10.1016/S0140-6736(15)60721-8

Ryg-Cornejo, V., Ioannidis, L. J., Ly, A., Chiu, C. Y., Tellier, J., Hill, D. L., et al. (2016). Severe malaria infections impair germinal center responses by inhibiting $\mathrm{T}$ follicular helper cell differentiation. Cell Rep. 14, 68-81. doi: 10.1016/j.celrep.2015.12.006

Sack, B. K., Keitany, G. J., Vaughan, A. M., Miller, J. L., Wang, R., and Kappe, S. H. (2015). Mechanisms of stage-transcending protection following immunization of mice with late liver stage-arresting genetically attenuated malaria parasites. PLoS Pathog. 11:e1004855. doi: 10.1371/journal. ppat. 1004855

Sagara, I., Dicko, A., Ellis, R. D., Fay, M. P., Diawara, S. I., Assadou, M. H., et al. (2009). A randomized controlled phase 2 trial of the blood stage AMA1-C1/Alhydrogel malaria vaccine in children in Mali. Vaccine 27, 3090-3098. doi: 10.1016/j.vaccine.2009.03.014

Sagara, I., Healy, S. A., Assadou, M. H., Gabriel, E. E., Kone, M., Sissoko, K., et al. (2018). Safety and immunogenicity of Pfs25H-EPA/alhydrogel, a transmission-blocking vaccine against Plasmodium falciparum: a randomised, double-blind, comparator-controlled, dose-escalation study in healthy Malian adults. Lancet Infect. Dis. 18, 969-982. doi: 10.1016/ S1473-3099(18)30344-X

Schussek, S., Trieu, A., Apte, S. H., Sidney, J., Sette, A., and Doolan, D. L. (2017). Novel Plasmodium antigens identified via genome-based antibody screen induce protection associated with polyfunctional $\mathrm{T}$ cell responses. Sci. Rep. 7:15053. doi: 10.1038/s41598-017-15354-0

Seder, R. A., Chang, L. J., Enama, M. E., Zephir, K. L., Sarwar, U. N., Gordon, I. J., et al. (2013). Protection against malaria by intravenous immunization with a nonreplicating sporozoite vaccine. Science 341, 1359-1365. doi: 10.1126/ science. 1241800

Sirima, S. B., Cousens, S., and Druilhe, P. (2011). Protection against malaria by MSP3 candidate vaccine. N. Engl. J. Med. 365, 1062-1064. doi: 10.1056/ NEJMc1 100670

Sissoko, M. S., Healy, S. A., Katile, A., Omaswa, F., Zaidi, I., Gabriel, E. E., et al. (2017). Safety and efficacy of PfSPZ vaccine against Plasmodium falciparum via direct venous inoculation in healthy malaria-exposed adults in Mali: a randomised, double-blind phase 1 trial. Lancet Infect. Dis. 17, 498-509. doi: 10.1016/\$1473-3099(17)30104-4

Smith, T., Ross, A., Maire, N., Chitnis, N., Studer, A., Hardy, D., et al. (2012). Ensemble modeling of the likely public health impact of a preerythrocytic malaria vaccine. PLoS Med. 9:e1001157. doi: 10.1371/journal. pmed. 1001157

Spring, M., Murphy, J., Nielsen, R., Dowler, M., Bennett, J. W., Zarling, S., et al. (2013). First-in-human evaluation of genetically attenuated Plasmodium falciparum sporozoites administered by bite of Anopheles mosquitoes to adult volunteers. Vaccine 31, 4975-4983. doi: 10.1016/j. vaccine. 2013.08.007

Stanisic, D. I., Fink, J., Mayer, J., Coghill, S., Gore, L., Liu, X. Q., et al. (2018). Vaccination with chemically attenuated Plasmodium falciparum asexual bloodstage parasites induces parasite-specific cellular immune responses in malarianaive volunteers: a pilot study. BMC Med. 16:184. doi: 10.1186/ s12916-018-1173-9

Sutherland, C. (2007). A challenge for the development of malaria vaccines: polymorphic target antigens. PLoS Med. 4:e116. doi: 10.1371/journal. pmed.0040116

Tarun, A. S., Peng, X., Dumpit, R. F., Ogata, Y., Silva-Rivera, H., Camargo, N., et al. (2008). A combined transcriptome and proteome survey of malaria parasite liver stages. Proc. Natl. Acad. Sci. U. S. A. 105, 305-310. doi: 10.1073/ pnas. 0710780104

Thera, M. A., Doumbo, O. K., Coulibaly, D., Laurens, M. B., Ouattara, A., Kone, A. K., et al. (2011). A field trial to assess a blood-stage malaria vaccine. N. Engl. J. Med. 365, 1004-1013. doi: 10.1056/NEJMoa1008115
Ting, L. M., Gissot, M., Coppi, A., Sinnis, P., and Kim, K. (2008). Attenuated Plasmodium yoelii lacking purine nucleoside phosphorylase confer protective immunity. Nat. Med. 14, 954-958. doi: 10.1038/nm.1867

Urban, B. C., Ferguson, D. J., Pain, A., Willcox, N., Plebanski, M., Austyn, J. M., et al. (1999). Plasmodium falciparum-infected erythrocytes modulate the maturation of dendritic cells. Nature 400, 73-77. doi: 10.1038/21900

Uwimana, A., Legrand, E., Stokes, B. H., Ndikumana, J. M., Warsame, M., Umulisa, N., et al. (2020). Emergence and clonal expansion of in vitro artemisinin-resistant Plasmodium falciparum kelch13 R561H mutant parasites in Rwanda. Nat. Med. 26, 1602-1608. doi: 10.1038/s41591-020-1005-2

Vaughan, A. M., Wang, R., and Kappe, S. H. (2010). Genetically engineered, attenuated whole-cell vaccine approaches for malaria. Hum. Vaccin. 6, 107-113. doi: 10.4161/hv.6.1.9654

Vijay, R., Guthmiller, J. J., Sturtz, A. J., Surette, F. A., Rogers, K. J., Sompallae, R. R., et al. (2020). Infection-induced plasmablasts are a nutrient sink that impairs humoral immunity to malaria. Nat. Immunol. 21, 790-801. doi: 10.1038/ s41590-020-0678-5

Volz, J. C., Yap, A., Sisquella, X., Thompson, J. K., Lim, N. T., Whitehead, L. W., et al. (2016). Essential role of the PfRh5/PfRipr/CyRPA complex during Plasmodium falciparum invasion of erythrocytes. Cell Host Microbe 20, 60-71. doi: 10.1016/j.chom.2016.06.004

Wahlgren, M., Goel, S., and Akhouri, R. R. (2017). Variant surface antigens of Plasmodium falciparum and their roles in severe malaria. Nat. Rev. Microbiol. 15, 479-491. doi: 10.1038/nrmicro.2017.47

Weiss, G. E., Crompton, P. D., Li, S., Walsh, L. A., Moir, S., Traore, B., et al. (2009). Atypical memory B cells are greatly expanded in individuals living in a malaria-endemic area. J. Immunol. 183, 2176-2182. doi: 10.4049/jimmunol.0901297

Weiss, G. E., Gilson, P. R., Taechalertpaisarn, T., Tham, W. H., de Jong, N. W., Harvey, K. L., et al. (2015). Revealing the sequence and resulting cellular morphology of receptor-ligand interactions during Plasmodium falciparum invasion of erythrocytes. PLoS Pathog. 11:e1004670. doi: 10.1371/journal. ppat. 1004670

WHO (2019). MVIP Countries: Ghana, Kenya, and Malawi. Available at: https:// www.who.int/immunization/diseases/malaria/malaria_vaccine_ implementation_programme/pilot_countries_ghana_kenya_malawi/en/ (Accessed January 10, 2021).

Wipasa, J., Xu, H., Stowers, A., and Good, M. F. (2001). Apoptotic deletion of Th cells specific for the 19-kDa carboxyl-terminal fragment of merozoite surface protein 1 during malaria infection. J. Immunol. 167, 3903-3909. doi: 10.4049/jimmunol.167.7.3903

Woodberry, T., Minigo, G., Piera, K. A., Amante, F. H., Pinzon-Charry, A., Good, M. F., et al. (2012). Low-level Plasmodium falciparum blood-stage infection causes dendritic cell apoptosis and dysfunction in healthy volunteers. J. Infect. Dis. 206, 333-340. doi: 10.1093/infdis/jis366

Woodberry, T., Pinzon-Charry, A., Piera, K. A., Panpisutchai, Y., Engwerda, C. R., Doolan, D. L., et al. (2009). Human T cell recognition of the blood stage antigen Plasmodium hypoxanthine guanine xanthine phosphoribosyl transferase (HGXPRT) in acute malaria. Malar. J. 8:122. doi: 10.1186/1475-2875-8-122

Wright, K. E., Hjerrild, K. A., Bartlett, J., Douglas, A. D., Jin, J., Brown, R. E., et al. (2014). Structure of malaria invasion protein RH5 with erythrocyte basigin and blocking antibodies. Nature 515, 427-430. doi: 10.1038/nature13715

Wu, Y., Ellis, R. D., Shaffer, D., Fontes, E., Malkin, E. M., Mahanty, S., et al. (2008). Phase 1 trial of malaria transmission blocking vaccine candidates Pfs 25 and Pvs25 formulated with montanide ISA 51. PLoS One 3:e2636. doi: 10.1371 /journal.pone.0002636

Wykes, M. N., Zhou, Y. H., Liu, X. Q., and Good, M. F. (2005). Plasmodium yoelii can ablate vaccine-induced long-term protection in mice. J. Immunol. 175, 2510-2516. doi: 10.4049/jimmunol.175.4.2510

Xu, H., Wipasa, J., Yan, H., Zeng, M., Makobongo, M. O., Finkelman, F. D., et al. (2002). The mechanism and significance of deletion of parasite-specific CD4(+) T cells in malaria infection. J. Exp. Med. 195, 881-892. doi: 10.1084/ jem.20011174

Zhu, F., Liu, T., Zhao, C., Lu, X., Zhang, J., and Xu, W. (2017). Whole-killed blood-stage vaccine-induced immunity suppresses the development of malaria parasites in mosquitoes. J. Immunol. 198, 300-307. doi: 10.4049/jimmunol.1600979

Conflict of Interest: The authors declare that the research was conducted in the absence of any commercial or financial relationships that could be construed as a potential conflict of interest. 
Copyright (c) 2021 Cai, Chen, Zhu, Lu, Liu and Xu. This is an open-access article distributed under the terms of the Creative Commons Attribution License (CC BY).

The use, distribution or reproduction in other forums is permitted, provided the original author(s) and the copyright owner(s) are credited and that the original publication in this journal is cited, in accordance with accepted academic practice. No use, distribution or reproduction is permitted which does not comply with these terms. 